\title{
APPLICATION OF NUMERICAL LAPLACE INVERSION Methods In Chemical Engineering With Maple®
}

\author{
Małgorzata Wójcik ${ }^{1}$, Mirosław Szukiewicz ${ }^{1}$, Paweł Kowalik ${ }^{2}$ \\ ${ }^{1}$ Department of Chemical and Process Engineering \\ Rzeszow University of Technology, Rzeszow, Poland \\ wojcik.mm@op.pl,ichms@prz.edu.pl \\ ${ }^{2}$ Institute of New Chemical Synthesis, Pulawy, Poland \\ pawel.kowalik@ins.pulawy.pl
}

\begin{abstract}
In this paper, the procedure of choice of the effective numerical inversion method of Laplace transform for solving of the mathematical model of gas flow was shown. Two inversion methods are evaluated in this work: the GaverStehfest method, and the Dubner and Abate method. The numerical tests has been made using test functions. Based on the test results the fast and accurate method was selected and applied for modeling of the gas flow. The GaverStehfest method has proven the most effective. The model was developed using the computer algebra system Maple ${ }^{\circledR}$. Implementation of the methods were done by authors.
\end{abstract}

Key words: numerical inversion of Laplace transform, gas flow model, Maple ${ }^{\circledR}$ program

\section{Introduction}

The Laplace transformation plays a significant role in mathematical applications in physics, mechanics, mathematics, economy, and computational sciences. It is a powerful tool for solving and analyzing of linear differential and linear integral equations. It is applicable in many areas of engineering mathematics and engineering systems e.g. for fluid flow and mass and energy transport in porous media were reported. Using of Laplace method technique greatly simplifies the solution of models representing sophisticated physical systems $[1,2,3,4]$. The inverse transform of a transfer function can be made by employing properties of Laplace transform and using tables of Laplace transform. A recent alternative are Computer Algebra Systems. Unfortunately, often it is impossible to find an inverse Laplace transform function analytical- 
ly. Then one can need a numerical approach, but it was reported that numerical inversion of Laplace transform can by numerically instable. On the other hand successful applications were also presented. For example, Chiang [5] suggested that best results, for solute the transport problems with groundwater, one can obtain by employing - the Crump method. Kocabas [6] presented two procedures of inverse Laplace transform, the Gaver-Stehfest method and the Dubner and Abate method to modeling of tracer transport in heterogeneous porous media. Author showed that the Dubner and Abate method was in this case the most powerful but also the most computationally expensive, while the Gaver-Stehfest method found the exact solution only for highly dispersive systems. Many scientists emphasized that the efficiency and accuracy of numerical Laplace inversion methods are different for various types of functions. Hassanzadeh and Pooladi-Darvish [7] found that the Gaver-Stehfest method can be applied for $\exp (-t)$ type of functions but this method fails when the solution is like $\exp (\mathrm{t})$, sinusoid and wave type of functions. The presented facts suggest that some algorithms can work best for certain types of problems, and they can fail for other types of problems. So, application of the method should be preceded by investigations.

In this work, we have undertaken an attempt to use numerical methods for inverse Laplace transform to solve a mathematical model related with gas flow through the measuring system. We examined, following Kocabas, two methods for the numerical inversion of transform function: the Gaver-Stehfest method, the Dubner and Abate method. The accuracy and computational efficiency of methods will be tested for their applicability for gas flow modeling. Methods was implemented in the system Maple ${ }^{\circledR}$.

The paper is organized as follows. In section 2 we show information about the numerical inversion Laplace methods. In Section 3, we examine the accuracy of the methods. The method chosen is examined for defined problem in Section 4. A discussion of the results and conclusions are presented in Section 5.

\section{The numerical methods}

There are many numerical inversion methods for Laplace transform. Each method has its own applications and is suitable for various problems in many domains, such as geology, mathematics, circuit theory, process control, and medicine. There are four main groups: (i) the Fourier series method, which is based on the Poisson summation formula, (ii) the Gaver-Stehfest algorithm, which is based on combinations of Gaver functional, (iii) the Weeks method, which is based on bilinear transformations and Laguerre expansions, (iv) the Talbot method, which is based on deforming the contour in the Bromwich inversion integral [8]. Based on results obtained by Kocabas [6] (similarity of 
problem considered by him), the Gaver-Stehfest method and the Dubner and Abate method were chosen for further tests.

\subsection{The Gaver-Stehfest method}

This method was developed in the late 1960s. It is very simple numerical inverse Laplace transform method which has been used in such diverse areas as chemistry, economics, mathematics, computational physics and engineering. This method is also employed for fluid flow problems $[5,6,7,9]$.

This method approximates the time domain solution as [10]

$$
f(t)=\frac{\ln 2}{t} \sum_{k=1}^{N} V_{k} \cdot F\left(k \cdot \frac{\ln 2}{t}\right)
$$

where $V_{k}$ is described by the following equation

$$
V_{k}=(-1)^{k+\frac{N}{2}} \sum_{j=\left(\frac{k+1}{2}\right)}^{\min \left(k, \frac{N}{2}\right)} \frac{j^{\frac{N}{2}}(2 j) !}{\left(\frac{N}{2}-j\right) ! j !(j-1) !(k-j) !(2 j-k) !}
$$

The parameter $\mathrm{N}$ is the number of terms used in Eq. (1). $\mathrm{N}$ must be an even integer and should be chosen by trial and error method. The precision of this method depends on the parameter $\mathrm{N}$. If $\mathrm{N}$ rises, accuracy of results, increases first and then the accuracy declines due to round-off errors [7]. Many authors propose a different value of the parameter $\mathrm{N}$ to obtain the best accuracy of this method. For example, Cheng and Sidauruk suggested that optimal choice of $\mathrm{N}$ should be in range from 6 to 20 [10], while Knight and Raiche recommended that $\mathrm{N}$ should be approximately equal to the number of decimal digits used by the computer in the calculation [11].

\subsection{The Fourier series method}

There are about 40 methods based on the Fourier series. These methods were first used by Dubner and Abate in 1968. Next, Durbin modified the method in 1973. The Fourier series technique for the Laplace inversion is based on choosing the contour of integration in the inversion integral, next converting the inversion integral into the Fourier transform, and finally approximating the transform by a Fourier series. The Fourier series method proposed by Dubner and Abate [9], is given by 


$$
f(t)=\frac{2 e^{a t}}{T}\left\{\frac{1}{2} \operatorname{Re}(F(s))+\sum_{k=1}^{N} \operatorname{Re}\left(F\left(a+\frac{k \pi i}{T}\right)\right) \cos \left(\frac{k \pi t}{T}\right)\right\}
$$

$T$ is the time interval; Re means the real part of a complex function.

It is known that the infinite series in equation converges very slowly which is the main obstacle in the efficient evaluation of the series.

The parameter $a$ is chosen as

$$
a=\alpha-\frac{\ln E}{2 T}
$$

where $E$ is the error tolerance, $\alpha$ is the real part of the leading pole of the function F(s) [10]. Lee et al. suggested values of at between 4 and 5 [7].

\section{Numerical examples}

This section presents results obtained for test functions. The numerical results were compared with the analytical solution in the real time domain. Different types of mathematical function was used for tests. The function with Example $\mathrm{A}$ is an periodic function. The function with Example B is an rapidly decreasing exponential function. The presence of this type functions of is expected in the solution of gas flow model. All numerical computations were performed using Maple 17 program. Calculations were made with precision up to 48 decimal digits. The results are presented in Tables.

\subsection{Example A}

In this example, we discuss the numerical inversion of Laplace transform for equation

$$
\mathcal{L}\{f(t)\}=F(s)=\frac{1}{s^{2}+s+1}
$$

The analytical form of inverse Laplace transform of (4) is

$$
f(t)=\frac{2}{3} \sqrt{3} \cdot e^{-\frac{1}{2} t} \cdot \sin \left(\frac{1}{2} \sqrt{3} \cdot t\right)
$$

The results are presented in Table 1, 2 and 3. For example, 5.335071E-01 means $5.335071 \cdot 10^{-1}$. 
Wójcik M., Szukiewicz M., Kowalik P.

Table 1. Exact and numerical solution for the function (4) for the Gaver-Stehfest method.

\begin{tabular}{|c|c|c|c|c|}
\hline \multirow{2}{*}{$\mathbf{t}$} & \multicolumn{3}{|c|}{ Approximate solution } & \multirow{2}{*}{ Exact solution } \\
\cline { 2 - 5 } & $\mathbf{N}=\mathbf{1 8}$ & $\mathbf{N}=\mathbf{3 0}$ & $\mathbf{N}=\mathbf{3 2}$ & \\
\hline $\mathbf{1}$ & $5.335071 \mathrm{E}-01$ & $5.335071 \mathrm{E}-01$ & $5.335071 \mathrm{E}-01$ & $5.335071 \mathrm{E}-01$ \\
\hline $\mathbf{2}$ & $4.192796 \mathrm{E}-01$ & $4.192796 \mathrm{E}-01$ & $4.192795 \mathrm{E}-01$ & $4.192796 \mathrm{E}-01$ \\
\hline $\mathbf{3}$ & $1.332426 \mathrm{E}-01$ & $1.332426 \mathrm{E}-01$ & $1.332426 \mathrm{E}-01$ & $1.332426 \mathrm{E}-01$ \\
\hline $\mathbf{4}$ & $-4.952987 \mathrm{E}-02$ & $-4.952987 \mathrm{E}-02$ & $-4.952987 \mathrm{E}-02$ & $-4.952987 \mathrm{E}-02$ \\
\hline $\mathbf{5}$ & $-8.794241 \mathrm{E}-02$ & $-8.794242 \mathrm{E}-02$ & $-8.794242 \mathrm{E}-02$ & $-8.794242 \mathrm{E}-02$ \\
\hline $\mathbf{6}$ & $-5.089245 \mathrm{E}-02$ & $-5.089231 \mathrm{E}-02$ & $-5.089229 \mathrm{E}-02$ & $-5.089231 \mathrm{E}-02$ \\
\hline $\mathbf{7}$ & $-7.643044 \mathrm{E}-03$ & $-7.643713 \mathrm{E}-03$ & $-7.643737 \mathrm{E}-03$ & $-7.643713 \mathrm{E}-03$ \\
\hline $\mathbf{8}$ & $1.271483 \mathrm{E}-02$ & $1.271509 \mathrm{E}-02$ & $1.271522 \mathrm{E}-02$ & $1.271509 \mathrm{E}-02$ \\
\hline $\mathbf{9}$ & $1.280100 \mathrm{E}-02$ & $1.280467 \mathrm{E}-02$ & $1.280464 \mathrm{E}-02$ & $1.280467 \mathrm{E}-02$ \\
\hline $\mathbf{1 0}$ & $5.387351 \mathrm{E}-03$ & $5.385480 \mathrm{E}-03$ & $5.385522 \mathrm{E}-03$ & $5.385480 \mathrm{E}-03$ \\
\hline
\end{tabular}

Table 2. Exact and numerical solution for the function (4) for the Dubner and Abate method.

\begin{tabular}{|c|c|c|c|c|}
\hline \multirow{2}{*}{$\mathbf{t}$} & \multicolumn{3}{|c|}{ Approximate solution } & \multirow{2}{*}{ Exact solution } \\
\cline { 2 - 5 } & $\mathbf{N}=\mathbf{5 0 0}$ & $\mathbf{N}=\mathbf{1 0 0 0}$ & $\mathbf{N}=\mathbf{1 0 0 0 0}$ & \\
\hline $\mathbf{1}$ & $5.335231 \mathrm{E}-01$ & $5.335031 \mathrm{E}-01$ & $5.335071 \mathrm{E}-01$ & $5.335071 \mathrm{E}-01$ \\
\hline $\mathbf{2}$ & $4.193116 \mathrm{E}-01$ & $4.192715 \mathrm{E}-01$ & $4.192795 \mathrm{E}-01$ & $4.192796 \mathrm{E}-01$ \\
\hline $\mathbf{3}$ & $1.332906 \mathrm{E}-01$ & $1.332305 \mathrm{E}-01$ & $1.332425 \mathrm{E}-01$ & $1.332426 \mathrm{E}-01$ \\
\hline $\mathbf{4}$ & $-4.946593 \mathrm{E}-02$ & $-4.954597 \mathrm{E}-02$ & $-4.953004 \mathrm{E}-02$ & $-4.952987 \mathrm{E}-02$ \\
\hline $\mathbf{5}$ & $-8.786249 \mathrm{E}-02$ & $-8.796254 \mathrm{E}-02$ & $-8.794262 \mathrm{E}-02$ & $-8.794242 \mathrm{E}-02$ \\
\hline $\mathbf{6}$ & $-5.079641 \mathrm{E}-02$ & $-5.091646 \mathrm{E}-02$ & $-5.089256 \mathrm{E}-02$ & $-5.089231 \mathrm{E}-02$ \\
\hline $\mathbf{7}$ & $-7.531829 \mathrm{E}-03$ & $-7.671887 \mathrm{E}-03$ & $-7.643997 \mathrm{E}-03$ & $-7.643713 \mathrm{E}-03$ \\
\hline $\mathbf{8}$ & $1.284295 \mathrm{E}-02$ & $1.268289 \mathrm{E}-02$ & $1.271477 \mathrm{E}-02$ & $1.271509 \mathrm{E}-02$ \\
\hline $\mathbf{9}$ & $1.294850 \mathrm{E}-02$ & $1.276844 \mathrm{E}-02$ & $1.280430 \mathrm{E}-02$ & $1.280467 \mathrm{E}-02$ \\
\hline $\mathbf{1 0}$ & $5.545293 \mathrm{E}-03$ & $5.345234 \mathrm{E}-03$ & $5.385075 \mathrm{E}-03$ & $5.385480 \mathrm{E}-03$ \\
\hline
\end{tabular}

Table 3. Comparison of numerical calculations for the function (4)

\begin{tabular}{|c|c|c|c|}
\hline \multicolumn{4}{|c|}{ The Gaver-Stehfest method } \\
\hline & $\mathrm{N}=18$ & $\mathbf{N}=\mathbf{3 0}$ & $\mathrm{N}=32$ \\
\hline Standard deviation & $5.90684 \mathrm{E}-07$ & $3.7104 \mathrm{E}-11$ & 8.4732E-09 \\
\hline Time of calculations [s] & 0.219 & 0.516 & 0.531 \\
\hline \multicolumn{4}{|c|}{ The Dubner and Abate method } \\
\hline & $\mathrm{N}=\mathbf{5 0 0}$ & $\mathrm{N}=1000$ & $\mathrm{~N}=10000$ \\
\hline Standard deviation & $4.4350 \mathrm{E}-05$ & $1.1168 \mathrm{E}-05$ & $1.1245 \mathrm{E}-07$ \\
\hline Time of calculations [s] & 30.875 & 66.125 & 1116.046 \\
\hline
\end{tabular}


Tests of the Gaver-Stehfest method were made for many values of parameter N. Accuracy of the method and time of computations increase as $\mathrm{N}$ increases up to $\mathrm{N}=30$. For larger value of $\mathrm{N}$ accuracy drops. For $\mathrm{N}=30$ time of calculations was acceptable.

Tests of the Dubner and Abate method show that accuracy of computations is lower than in previous tests. Similar (but still lower) accuracy as the GaverStehfest method was obtained for $\mathrm{N}=10000$ for which time of computations was approximately 2000 times longer (about 20 minutes). Obtained results show that for case A better method of solution finding is the Gaver-Stehfest method.

\subsection{Example B}

In this example, both the Gaver-Stehfest method and the Dubner and Abate method are used to calculate the inverse Laplace transformation of equation

$$
\mathcal{L}\{f(t)\}=F(s)=\frac{1}{\sqrt{s}+\sqrt{s+1}}
$$

The analytical inverse Laplace transform of (6) is

$$
f(t)=\frac{1-e^{-t}}{\sqrt{4 \pi t^{3}}}
$$

The results are presented in Table 4, 5 and 6.

Table 4. Exact and numerical solution for the function (6) the Gaver-Stehfest method

\begin{tabular}{|c|c|c|c|c|}
\hline \multirow{2}{*}{$\mathbf{t}$} & \multicolumn{3}{|c|}{ Approximate solution } & \multirow{2}{*}{ Exact solution } \\
\cline { 2 - 5 } & $\mathbf{N}=\mathbf{1 0}$ & $\mathbf{N}=\mathbf{2 8}$ & $\mathbf{N}=\mathbf{3 0}$ & \\
\hline $\mathbf{1}$ & $1.783179 \mathrm{E}-01$ & $1.783179 \mathrm{E}-01$ & $1.783179 \mathrm{E}-01$ & $1.783179 \mathrm{E}-01$ \\
\hline $\mathbf{2}$ & $8.623782 \mathrm{E}-02$ & $8.623782 \mathrm{E}-02$ & $8.623798 \mathrm{E}-02$ & $8.623782 \mathrm{E}-02$ \\
\hline $\mathbf{3}$ & $5.158626 \mathrm{E}-02$ & $5.158626 \mathrm{E}-02$ & $5.158626 \mathrm{E}-02$ & $5.158626 \mathrm{E}-02$ \\
\hline $\mathbf{4}$ & $3.461599 \mathrm{E}-02$ & $3.461600 \mathrm{E}-02$ & $3.461601 \mathrm{E}-02$ & $3.461600 \mathrm{E}-02$ \\
\hline $\mathbf{5}$ & $2.506131 \mathrm{E}-02$ & $2.506131 \mathrm{E}-02$ & $2.506131 \mathrm{E}-02$ & $2.506131 \mathrm{E}-02$ \\
\hline $\mathbf{6}$ & $1.914654 \mathrm{E}-02$ & $1.914654 \mathrm{E}-02$ & $1.914655 \mathrm{E}-02$ & $1.914654 \mathrm{E}-02$ \\
\hline $\mathbf{7}$ & $1.521782 \mathrm{E}-02$ & $1.521779 \mathrm{E}-02$ & $1.521779 \mathrm{E}-02$ & $1.521779 \mathrm{E}-02$ \\
\hline $\mathbf{8}$ & $1.246279 \mathrm{E}-02$ & $1.246276 \mathrm{E}-02$ & $1.246274 \mathrm{E}-02$ & $1.246276 \mathrm{E}-02$ \\
\hline $\mathbf{9}$ & $1.044669 \mathrm{E}-02$ & $1.044666 \mathrm{E}-02$ & $1.044666 \mathrm{E}-02$ & $1.044666 \mathrm{E}-02$ \\
\hline $\mathbf{1 0}$ & $8.920229 \mathrm{E}-03$ & $8.920215 \mathrm{E}-03$ & $8.920219 \mathrm{E}-03$ & $8.920215 \mathrm{E}-03$ \\
\hline
\end{tabular}


Wójcik M., Szukiewicz M., Kowalik P.

Table 5. Exact and numerical solution for the function (6) the Dubner and Abate method

\begin{tabular}{|c|c|c|c|c|}
\hline \multirow{2}{*}{$\mathbf{T}$} & \multicolumn{3}{|c|}{ Approximate solution } & \multirow{2}{*}{ Exact solution } \\
\cline { 2 - 5 } & $\mathbf{N}=\mathbf{5 0 0}$ & $\mathbf{N}=\mathbf{1 0 0 0}$ & $\mathbf{N}=\mathbf{1 0 0 0 0}$ & \\
\hline $\mathbf{1}$ & $5.335231 \mathrm{E}-01$ & $5.335031 \mathrm{E}-01$ & $5.335071 \mathrm{E}-01$ & $5.335071 \mathrm{E}-01$ \\
\hline $\mathbf{2}$ & $4.193116 \mathrm{E}-01$ & $4.192715 \mathrm{E}-01$ & $4.192795 \mathrm{E}-01$ & $4.192796 \mathrm{E}-01$ \\
\hline $\mathbf{3}$ & $1.332906 \mathrm{E}-01$ & $1.332305 \mathrm{E}-01$ & $1.332425 \mathrm{E}-01$ & $1.332426 \mathrm{E}-01$ \\
\hline $\mathbf{4}$ & $-4.946593 \mathrm{E}-02$ & $-4.954597 \mathrm{E}-02$ & $-4.953004 \mathrm{E}-02$ & $-4.952987 \mathrm{E}-02$ \\
\hline $\mathbf{5}$ & $-8.786249 \mathrm{E}-02$ & $-8.796254 \mathrm{E}-02$ & $-8.794262 \mathrm{E}-02$ & $-8.794242 \mathrm{E}-02$ \\
\hline $\mathbf{6}$ & $-5.079641 \mathrm{E}-02$ & $-5.091646 \mathrm{E}-02$ & $-5.089256 \mathrm{E}-02$ & $-5.089231 \mathrm{E}-02$ \\
\hline $\mathbf{7}$ & $-7.531829 \mathrm{E}-03$ & $-7.671887 \mathrm{E}-03$ & $-7.643997 \mathrm{E}-03$ & $-7.643713 \mathrm{E}-03$ \\
\hline $\mathbf{8}$ & $1.284295 \mathrm{E}-02$ & $1.268289 \mathrm{E}-02$ & $1.271477 \mathrm{E}-02$ & $1.271509 \mathrm{E}-02$ \\
\hline $\mathbf{9}$ & $1.294850 \mathrm{E}-02$ & $1.276844 \mathrm{E}-02$ & $1.280430 \mathrm{E}-02$ & $1.280467 \mathrm{E}-02$ \\
\hline $\mathbf{1 0}$ & $5.545293 \mathrm{E}-03$ & $5.345234 \mathrm{E}-03$ & $5.385075 \mathrm{E}-03$ & $5.385480 \mathrm{E}-03$ \\
\hline
\end{tabular}

Table 6. Comparison of numerical calculations for the function (6)

\begin{tabular}{|c|c|c|c|}
\hline \multicolumn{4}{|c|}{ The Gaver-Stehfest method } \\
\hline & $\mathbf{N}=\mathbf{1 0}$ & $\mathbf{N}=\mathbf{2 8}$ & $\mathbf{N}=\mathbf{3 0}$ \\
\hline Standard deviation & $7.8655 \mathrm{E}-09$ & $1.4790 \mathrm{E}-11$ & $2.0181 \mathrm{E}-08$ \\
\hline Time of calculations [s] & 0.219 & 0.641 & 0.734 \\
\hline \multicolumn{4}{|c|}{ The Dubner and Abate method } \\
\hline & $\mathrm{N}=\mathbf{5 0 0}$ & $\mathrm{N}=1000$ & $\mathrm{~N}=10000$ \\
\hline Standard deviation & $1.0812 \mathrm{E}-02$ & 7.6397E-03 & $2.4141 \mathrm{E}-03$ \\
\hline Time of calculations [s] & 91.484 & 185.875 & 3193.500 \\
\hline
\end{tabular}

Tests of the Gaver-Stehfest method was applied for many values of parameter N. Accuracy of the method and time of increase as $\mathrm{N}$ increases up to $\mathrm{N}=28$. For next value of $\mathrm{N}$ accuracy drops. For $\mathrm{N}=28$ time of calculations was acceptable $(\mathrm{t}=0.641 \mathrm{~s})$ thus $\mathrm{N}=28$ was an optimal value of parameter $\mathrm{N}$ for Example B.

Tests of the Dubner and Abate method show that accuracy of computations is lower than in previous tests. Similar (but still lower) accuracy as the GaverStehfest method was obtained for $\mathrm{N}=10000$ for which time of computations was approximately 4500 times longer (about 50 minutes). Obtained results show that for case B better method of solution finding is the Gaver-Stehfest method.

The tests performed showed that in investigated cases faster and more accurate procedure is the Gaver-Stehfest algorithm and this method will be used for a real measurement system. 


\section{Results}

In the previous section, we have chosen the Gaver-Stehfest algorithm as the best method. Now, we will test, whether the Gaver-Stehfest method can be used for solving of the model of real gas flow process. The measurement unit, its application and the model of the unit were described in details in [1]. Founded there The final form of the model in Laplace domain is eq. (8). The proper $\mathrm{n} 1 . . . \mathrm{n} 4$ values were determined by trial and error method in [1].

$c_{4, n 4}=\frac{1}{s} \cdot\left[\left(\frac{q}{n 4 \cdot V_{c 4} \cdot s+q}\right)^{n 4}\left(\frac{q}{n 3 \cdot V_{c 3} \cdot s+q}\right)^{n 3}\left(\frac{q}{n 2 \cdot V_{c 2} \cdot s+q}\right)^{n 2} \cdot c_{i n}+\left(\frac{q}{n 4 \cdot V_{c 4} \cdot s+q}\right)^{n 4} \cdot c_{i n}\right] \cdot e^{-t_{d} s}$

where:

$c_{4, n 4}$ - outlet concentration of gas, measured by TCD detector

$q-$ gas flow $\left[\mathrm{dm}^{3} / \mathrm{min}\right]$

$c_{\text {in }}$ - gas concentration in inlet to zone $0\left[\mathrm{~mol} / \mathrm{dm}^{3}\right]$

$V_{c k}$ - volume of a single cell in $k$-th cell $\left[\mathrm{dm}^{3}\right]$

$c_{j, k}-$ gas concentration in $j$-th zone, in cell $k\left[\mathrm{~mol} / \mathrm{dm}^{3}\right]$

$t \quad$ - time [min]

$t_{d} \quad$ - time delay

$s \quad$ - complex variable.

Eq. (8) was solved using the Gaver-Stehfest method. Computations were done for following parameters: gas flow $-0.01 \mathrm{dm}^{3} / \mathrm{min}$. Numbers of cells in each of zones: $\mathrm{n} 1=1, \mathrm{n} 2=12, \mathrm{n} 3=1, \mathrm{n} 4=1$. Calculations were carried out using Maple $^{\circledR}$ with precision up to 48 decimal digits. Results are presented on Figure 1. 




Figure 1. Screenshot of program Maple ${ }^{\circledR}$. Numerical, theoretical and experimental profiles gas concentrations for $0.01 \mathrm{dm}^{3} / \mathrm{min}$. The Gaver-Stehfest method

The results will be compared with those presented in [1]. The computations performed showed, that the Gaver-Stehfest method can solve the gas flow problem with high accuracy (minimal standard deviation is equal to 1.7E-07, obtained for $\mathrm{N}=30$ ) and fast (time of calculations $\mathrm{t}=1.18 \mathrm{~s}$ for $\mathrm{N}=30$ ). The tests presented in section 3 enable to carry out calculations for the gas flow model without numerical problems. Even determining number of terms for Gaver functional seems to be correct, although in investigated case a bit of more accurate results were obtained for $\mathrm{N}=34$. In our opinion it means that value of $\mathrm{N}$ should be fitted to the final model (if possible), but results for $\mathrm{N}=30$ (the optimal value of $\mathrm{N}$ for test functions) are also satisfactory. 


\section{Conclusions}

On the basis of performed calculations, the following conclusions can be drawn:

1. The Gaver-Stehfest method is very effective algorithm for solution of gas flow problem. It works fast and with high accuracy.

2. The preliminary tests of methods of numerical inverse Laplace transform is purposeful. They are contradictory reports in literature and the tests may allow the elimination of wrong or time-consuming procedures.

Test functions should contain the terms, the presence of which is expected in the problem solution.

\section{Appendices}

This work was supported by The National Centre for Research and Development (Poland) under a grant PBS1/A1/6/2012.

\section{References}

1. Wójcik M., Szukiewicz M., Kowalik P., 2014, The application of the Laplace transform for modeling of gas flow using Maple ${ }^{\circledR}$, The Journal of Applied Computer Science Methods, vol. 6, pp. 43-53

2. Gaul L., Schanz M., 1999, A comparative study of three boundary element approaches to calculate the transient response of viscoelastic solids with unbounded domains, Computational Methods in Applied Mathematics, vol. 179, pp. 111123

3. Mathur R., Poonia S., 2013, Application of Laplace transform to Newtonian fluid problems, Journal of Science and Research, vol. 2, pp. 358-361

4. Coronado M., Ramirez-Sabag J., Valdiviezio-Mijangos O., 2007, On the boundary conditions in tracer transport model for fractured porous underground formations, Revista Mexicana De Fisica, vol. 53, pp. 260-269

5. Chiang Li-Wei., 1989, The application of numerical Laplace inversion methods to groundwater flow and solute transport problems, New Mexico Institute of Mining and Technology, New Mexico

6. Kocabas I., 2011, Application of iterated Laplace transformation to tracer transients in heterogeneous porous media, Journal of the Franklin Institute, vol. 348, pp. $1339-1362$

7. Hassanzadeh H., Poolad-Darvish M., 2007, Comparison of different numerical Laplace inversion methods for engineering application, Applied Mathematics and Computation, vol. 189, pp. 1966-1981

8. Abate J., Valkó P., 2004, Multi-precision Laplace transform inversion, International Journal for Numerical Methods in Engineering, vol. 60, pp. 979-993 
9. Wang Q., Zhan H., 2015, On different numerical inverse Laplace methods for solute transport problems, Advances in Water Resources, vol. 75, pp. 80-92

10. Cheng A., Sidauruk P., 1994, Approximate inversion of the Laplace transform, The Mathematical Journal, vol. 4, pp.76-82

11. Knight J.H., Raiche A.P., 1982, Transient electromagnetic calculations using the Gaver-Stehfest inverse Laplace transform method, Geophysics, vol. 47, pp. 4750 